\title{
Programmed Cell Death Ligand-1 (PDL-1) Correlates With Tumor Infiltration by Immune Cells and Represents a Promising Target for Immunotherapy in Endometrial Cancer
}

\author{
THOMAS HECKING ${ }^{1 *}$, THORE THIESLER ${ }^{2 *}$, JANINA HALBE $^{1}$, LUCIA OTTEN $^{1}$, FLORIAN RECKER $^{1}$, \\ HEIDRUN GEVENSLEBEN ${ }^{2}$, TIM MÜLLER ${ }^{2}$, CYNTHIA SCHILLER ${ }^{2}$, EVA K. EGGER ${ }^{1}$, ROLF FIMMERS $^{3}$, \\ MATTHIAS B. STOPE ${ }^{1}$, GLEN KRISTIANSEN ${ }^{2 \#}$ and ALEXANDER MUSTEA ${ }^{1 \#}$ \\ ${ }^{1}$ Department of Gynecology and Gynecological Oncology, \\ Center for Integrated Oncology, University of Bonn, Bonn, Germany; \\ ${ }^{2}$ Institute of Pathology, Center for Integrated Oncology, University of Bonn, Bonn, Germany; \\ ${ }^{3}$ Institute of Medical Biometry, Informatics and Epidemiology, \\ Center for Integrated Oncology, University of Bonn, Bonn, Germany
}

\begin{abstract}
Background/Aim: Endometrial carcinoma (EC) is one of the most common gynecological cancers in the Western Hemisphere. Nevertheless, there are not enough appropriate treatment options, especially for advanced stages. The immune checkpoint blockade represents a promising alternative to established cancer therapies by suppressing the immune-inhibitory activity of the immune checkpoint factors programmed cell death-1 (PD-1) and programmed cell death ligand-1 (PD-L1). In the present study, we characterized the clinical relevance of the biomarker PD-L1 expression in terms of its prognostic capabilities in EC. Patients and Methods: Tumor tissue samples from 87 EC patients were retrospectively analyzed by immunohistochemistry (PD-L1, p16, estrogen receptor, progesterone receptor, HER2/neu, Ki67, CD3, CD20, CD68). Results: A total of $17.3 \%$ of EC patients were $P D-L 1$ positive. $P D-L 1$ status did not represent a suitable prognostic marker in EC, but correlated with
\end{abstract}

\footnotetext{
*\#These Authors contributed equally to this study.

Correspondence to: Matthias Stope, Department of Gynecology and Gynecological Oncology, Center for Integrated Oncology, University of Bonn, Venusberg-Campus 1, 53127 Bonn, Germany. Tel: +49 22828711361, Fax: +49 22828716091, e-mail: matthias.stope@ukbonn.de
}

Key Words: Endometrium cancer, PD-L1, PD-1, immune checkpoint, prognostic factor, targeted therapy.

This article is an open access article distributed under the terms and conditions of the Creative Commons Attribution (CC BY-NC-ND) 4.0 international license (https://creativecommons.org/licenses/by-nc-nd/4.0).
T3/T4stage, positive lymph node status, p16 expression, and absence of estrogen and progesterone receptor. PD-LI positive tissues showed increased infiltration with lymphocytes, monocytes, and macrophages, although not statistically significant in every case. Conclusion: In EC, PDL1 expression has no prognostic significance, but correlates with other oncogenic factors and indicates increased infiltration of the tumor with immune cells. Thus, PD-1/PDL1 immunecheckpoint blockade seems to be very promising, at least in a subset of EC patients.

Endometrial cancer (EC) is one of the most common gynecological malignancies in the western hemisphere including Germany. Due to demographic change and increasing rate of obesity, which is one of the most important risk factors of EC, the incidence of this malignancy is rising $(1,2)$. There are two different EC subtypes: Type 1 is the estrogen-related endometrial EC and type 2 exhibits histological subtypes such as serous or clear cell carcinoma. Type $1 \mathrm{EC}$ are the most common and have good prognosis if diagnosed early. Type 2 EC tend to behave malignantly like ovarian cancer. If diagnosed at an early stage, type 1 EC has a very good prognosis and can be treated by surgery alone. Type $2 \mathrm{EC}$, in contrast, necessitates a more sophisticated treatment regimen including a staging procedure similar to ovarian cancer therapy and adjuvant chemotherapy. Recurrent EC has a very poor prognosis and further treatment options need to be evaluated to prolong the overall survival. Other factors, such as cancer genetics, pole mutations, MSI Status, and copy-number low or high demonstrate other properties of EC (3-6).

An essential hallmark for tumor cell survival and progression is the evasion from the body's immune system. Therapeutics that can restore the blocked interaction of 
Table I. Antibodies used for immunohistochemical analysis.

\begin{tabular}{lcccc}
\hline Antigen & \multicolumn{1}{c}{ Isotype } & Clone & Dilution & Manufacturer \\
\hline CD3 & IgG2a, mouse, monoclonal & PS1 & $1: 50$ & Novocastra, Newcastle Upon Tyne, England \\
CD20 & IgG2a, mouse, monoclonal & L26 & $1: 2,000$ & Dako, Glostrupp, Danmark \\
CD68 & IgG3, mouse, monoclonal & PG-M1 & $1: 250$ & Dako, Glostrupp, Danmark \\
HER2/neu & VENTANA anti-HER2/neu, monoclonal & 4 B5 & Pre-diluted & Roche, Basel, Suisse \\
Ki-67 & IgG1, mouse, monoclonal & MIB-1 & $1: 500$ & Dako, Glostrupp, Danmark \\
Estrogen receptor & CONFIRM anti-ER (monoclonal) & SP1 & Pre-diluted & Roche, Basel, Suisse \\
PD-L1 & IgG1, mouse, monoclonal & $22 \mathrm{C} 3$ & $1: 25$ & Dako, Glostrupp, Danmark \\
Progesterone receptor & CONFIRM anti-PR (monoclonal) & 1E2 & Pre-diluted & Roche, Basel, Suisse \\
p16INK4A & CINtec Histology Kit & - & - & Roche, Basel, Suisse \\
\hline
\end{tabular}

immune system components with tumor cells are therefore an innovative and promising treatment approach in cancer therapy. One of the most important immune checkpoints is the receptor programmed cell death-1 (PD-1), which is, among others, expressed on activated $\mathrm{T}$ lymphocytes. This receptor interacts with programmed cell death ligand-1 (PD-L1), which is frequently expressed on cancer cells (7). By binding tumorderived PD-L1 to PD-1 of lymphocytes, cancer cells can induce local suppression of the cancer-specific immune response. Membrane-bound expression of PD-L1 on tumors is therefore often associated with poor prognosis (8-10).

In contrast to EC, a therapeutic blockade of the PD-1/PDL1 immune checkpoint is already used in clinical practice for other malignancies (11). This rises the question of whether PD-L1 is also expressed in EC and whether this could potentially have an impact on the clinical course of EC. Thereby, PD-L1 might not only represent a prognostic biomarker in EC, but might also represent a promising target for immunotherapeutic interventions.

The aim of the present study was to histochemically characterise PD-L1 status of EC patient samples and its possible correlation with further clinical factors. This allows the evaluation of PD-L1 expression as a prognostic factor. Furthermore, it can be analyzed whether EC patients might benefit from a directed PD-L1 blockade therapy.

\section{Patients and Methods}

Patients. The patient collective consisted of 103 patients who were diagnosed and treated with EC at the Department of Gynecology and Gynecological Oncology at the University Hospital Bonn (Germany) between 2002 and 2016. Due to the absence of tumor tissue and the washout of tumor tissue on slides, the group size of the collective was decimated by 18 patients $(15.5 \%)$. Thus, the final size of the collective consisted of 87 patients. This study was conducted in accordance with the standards of the local ethics committee of the Medical Faculty of the Rheinische FriedrichWilhelms-University of Bonn (Bonn, Germany, Nr: 233/20).

Treatment and therapy were in accordance with current guidelines. Clinical data were collected using the clinical database of the Gynaecological Cancer Centre at Universtity Hospital Bonn (Germany) and the database of the Institute of Pathology Bonn (Germany), as well as individual archived files. Patient follow-up was performed using the above databases or, when possible, by personal contact. The Institute of Pathology Bonn prepared the histopathological analysis with determination of the tumor stage of the tissue samples. This was based on the $7^{\text {th }}$ FIGO/TNM classification of EC from 2010 (12). Adapted to the change in the FIGO/TNM system, all malignancies diagnosed before 2010 are classified according to the currently valid staging.

Tissue microarray (TMA). TMA samples were punched from formalin-fixed blocks and embedded in kerosene. Each punch contained one tissue section. These sections were applied in rows one after the other on the slide (13). Representative tumor areas on the TMA specimens were stained with hematoxylin-eosin stain. Two punches were selected from the tumor areas for each patient. The diameter of each punch was $1 \mathrm{~mm}$. This resulted in a punched area of $0.785 \mathrm{~mm}^{2}$. The punches were processed into multiple TMA slides. One slide contained up to 84 punches.

Immunohistochemistry. Immunohistochemical staining was performed using DakoCytomation (DAKO TechMate 500; DAKO, Glostrup, Denmark) and VENTANA BenchMark Ultra series (Ventana Medical Systems, Tucson, Arizona, USA) stainers with Ventana Amplifier Detection Kit. PDL-1, CD3, CD20, CD68, p16, HER2/neu, ER, PR, and Ki-67 were analyzed (Table I). Immunohistochemically stained tissue preparations were evaluated using a Leica DM LB2 microscope (Leica Mikrosysteme, Wetzlar, Germany) with Pannoramic Viewer (3DHistech, Budapest, Hungary) and Axio Observer D1 microscope (Zeiss, Jena, Germany) with Axio Vision version 4.7 (Zeiss) for wide-field microscopy. Selected areas of kidney specimens served as negative controls, and sections of tonsil specimens served as positive controls.

PD-L1 staining of tumor cells was considered positive when continuous staining of cell membranes was observed. The classification of the degree of staining was divided into the four categories 0 (no staining), 1+ (mild staining), 2+ (moderate staining), and 3+ (strong staining; Figure 1A-D). In addition, the percentage of stained tumor cells was estimated. Tumor areas with a staining intensity of $\geq 1+$ with a percentage of $\geq 1 \%$ of tumor cells were considered positive.

$\mathrm{Ki}-67$ positive tumor cells were determined in percentage (Figure $1 \mathrm{E})$. Cells with a staining rate of $30 \%$ or higher in the nucleus and cytoplasm were considered p16 positive. HER2/neu positive cells 

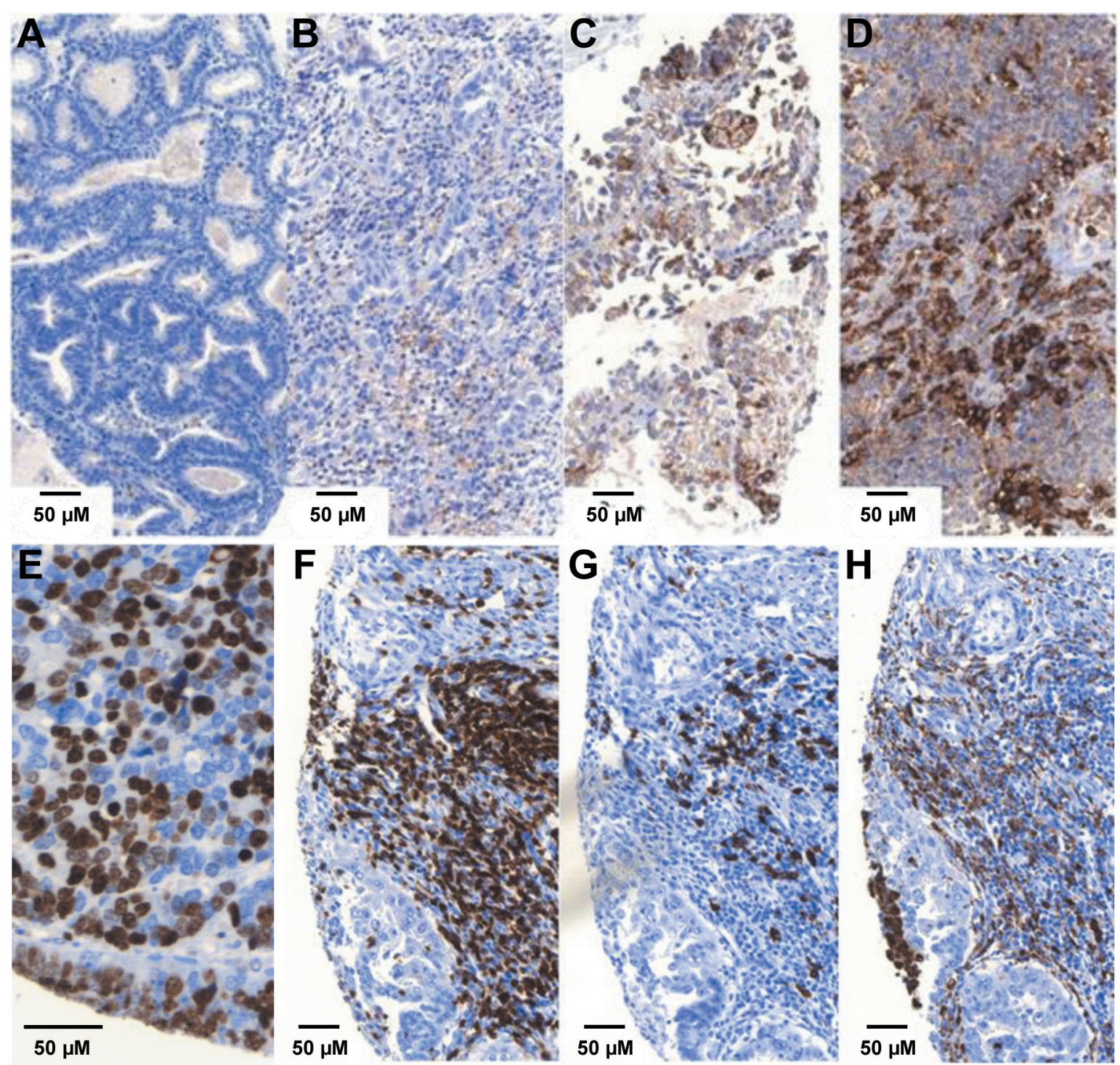

Figure 1. PD-L1 staining categories $0(A),+1(B),+2(C)$, and $+3(D)$, Ki67 staining $(E)$, and staining of CD3 positive $(F), C D 20$ positive $(G)$, and $C D 68$ positive $(H)$ immune cells.

were considered to be $3+$ staining or higher according to the American Society of Oncology and College of American Pathologists (ASCO/CAP) grading system. Immune cells were differentiated into $\mathrm{CD} 3$ positive (T lymphocytes), CD20 positive (B lymphocytes), and CD68 positive (monocytes/macrophages) cells (Figure 1F-H). Values were reported separately for the epithelial and stromal regions. For progesterone receptor expression analysis, samples were indicated as positive if they had a staining intensity $>1+$ and staining $>10 \%$ of all cells. Estrogen receptor positive was defined as a staining intensity $>1+$ and a staining of $>1 \%$ of all cells.

Statistics. Statistical analysis was performed using SPSS software version 25.0 (IBM, Chicago, IL, USA). The following analyses were performed: Chi-square test, cross-tabulation, Kaplan-Meier survival analysis, Student's $t$-test, and Cox regression analysis. A graphical representation of the individual evaluations was made using Kaplan-Meier curves and histograms. $p \leq 0.050$ was defined as statistically significant.

\section{Results}

The parameters of 103 EC patients treated in our Gynecological Cancer Center between 2002 and 2013 were analyzed. Due to the poor sample quality, only 87 of 103 patients could be evaluated immunohistochemically. The ages of these 87 patients ranged from 33 to 89 years with a median of 63 years (Table II). The average body mass index was 
Table II. Patient characteristics.

\begin{tabular}{lcc}
\hline Age & Median (years) & Range (years) \\
Body mass index & 63.6 & $33.0-89.2$ \\
& Median & Range \\
Histological subtype & 30.5 & $14.7-58.1$ \\
Endometroid & No. & $\%$ \\
Serous & 79 & 90.8 \\
Clear cell & 3 & 3.4 \\
Neuroendocrine & 0 & 0.0 \\
Mucinous & 0 & 0.0 \\
Undifferentiated & 0 & 0.0 \\
N/A & 1 & 1.1 \\
Grading & 4 & 4.6 \\
Grade 1 & No. & $\%$ \\
Grade 2 & 9 & 10.3 \\
Grade 3 & 55 & 63.2 \\
N/A & 20 & 24.1 \\
Tumor size & 2 & 2.3 \\
T1 & No. & $\%$ \\
T2 & 56 & 64.4 \\
T3 & 15 & 17.2 \\
T4 & 13 & 14.9 \\
N/A & 1 & 1.1 \\
\hline
\end{tabular}

No.: Number, N/A: not available.

30.5. The majority of EC were of endometroid histology $(90.8 \%)$ and showed grade $3(62.1 \%)$, and tumor size of $\mathrm{T} 1$ (64.4\%).

The prognostic relevance of histological subtypes, grading, and tumor size was assessed by Kaplan-Meier survival analysis. Patients with endometroid EC showed longer recurrence-free survival (50 months) and overall survival (53 months) compared with serous EC patients (Figure 2A and B). A comparison of grade 1 and grade 2 patients with grade 3 EC patients also showed differences in survival depending on tumor grading. These differences included 31 months for recurrence-free survival and 28 months for overall survival (Figure 2C and D). Similar results were seen when stages T1 and T2 were compared with both stages T3 and T4. Patients in the $\mathrm{T} 1+\mathrm{T} 2$ group showed both longer recurrence-free survival (78 months) and longer overall survival (81 months; Figure 2E and F).

Regarding PD-L1 expression, only 15 (17.3\%) of the total 87 patients tested PD-L1 positive (Table III). In T1 + T2 tumors, $11.0 \%$ were PD-L1 positive, while in T3 and T4 stage tumors, $43.0 \%$ were PD-L1 positive. The expression of the protein correlated statistically significantly with the higher stages of the T3 + T4 group $(p=0.010)$. Furthermore, it was also shown that the majority of lymph node status positive patients expressed PD-L1 (86.0\%). Again, the correlation of lymph node status positive and PD-L1 expression was statistically significant $(p=0.008)$.
The tumor suppressive cell-cycle regulator p16 was identified as another factor that correlated with PD-L1 expression. Of the $10(11.5 \%)$ p16 positive patients, $60.0 \%$ were also PD-L1 positive. The expression of p16 and PD-L1 correlated positively with each other $(p=0.001)$. There was a negative correlation in estrogen and progesterone receptor expression. A total of $9.2 \%$ (estrogen receptor) and $25.3 \%$ (progesterone receptor) of patients were receptor negative. The absence of the estrogen receptor $(p=0.027)$ and the progesterone receptor $(p=0.002)$ correlated statistically significantly with PD-L1 expression. Another important regulator of EC progression is HER2/neu. A total of 79 (90.8\%) patients were HER2/neu negative and also exhibited a low incidence of PD-L1 positive cases (16.5\%). Vice versa, $8(9.2 \%)$ patients were HER2/neu positive, of which $25.0 \%$ were PD-L1 positive. Statistical analysis indicated no correlation of HER2/neu and PD-L1 expression in EC $(p=0.417)$. Similarly, cell cycle factor Ki-67 was also not correlated with PD-L1 expression. The analysis was performed on Ki-67 positive cells per preparation and demonstrated a broad distribution from $0.09 \%$ to $79.5 \% \mathrm{Ki}$ 67 positive cells per patient sample. No correlation of Ki-67 and PD-L1 was detected in EC cells $(p=0.738)$.

Considering the immunosuppressive efficacy of PD-L1, the interaction of PD-L1 expression and the presence of immune cells in EC tissue was analyzed. For this aim, the number of $\mathrm{T}$ lymphocytes (CD3 positive), B lymphocytes (CD20 positive), and monocytes/macrophages (CD68 positive) were determined and correlated with PD-L1 status separately for intratumoral and peritumoral localization, expressed as immune cells per $0.785 \mathrm{~mm}^{2}$ tumor tissue.

$\mathrm{T}$ lymphocyte infiltration could be assessed in 86 (intratumoral) and 84 (peritumoral) patients of the collective (Table IV). Analysis of tumor-associated T lymphocytes revealed that in PD-L1 positive tissue areas, both intratumorally and extratumorally, about 1.8-fold more CD3 positive cells per $0.785 \mathrm{~mm}^{2}$ were detectable than in PD-L1 negative tumor tissue. However, despite this tendency, the Mann-Whitney $U$-test did not provide statistical significance for this observation (intratumoral: $p=0.154$; peritumoral: $p=0.175$ ).

The evaluation of tumor-associated B lymphocytes could be performed in 86 intratumoral as well as peritumoral sections of each of the $87 \mathrm{EC}$ patient samples (Table V). The difference of PD-L1 positive versus PD-L1 negative samples was even more pronounced here than in CD3 positive $T$ lymphocytes and was apparent in both intratumoral (19 vs. 1) and peritumoral sections (256 vs. 33). In the intratumoral sections, PD-L1 expression correlated statistically significantly with the presence of B lymphocyte-specific CD20 immune signals $(p=0.012)$. Differences in peritumoral CD20 and PD-L1 staining were not statistically significant $(p=0.107)$. Moreover, compared with PD-L1 negative tumor 
A

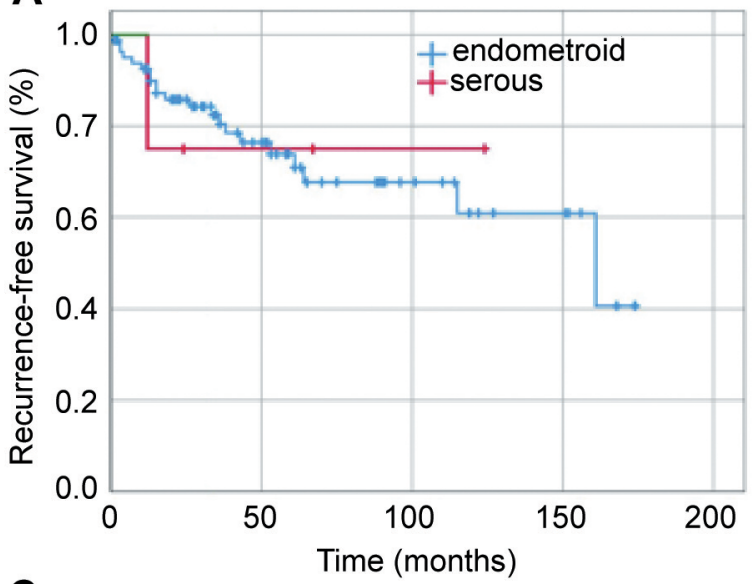

C

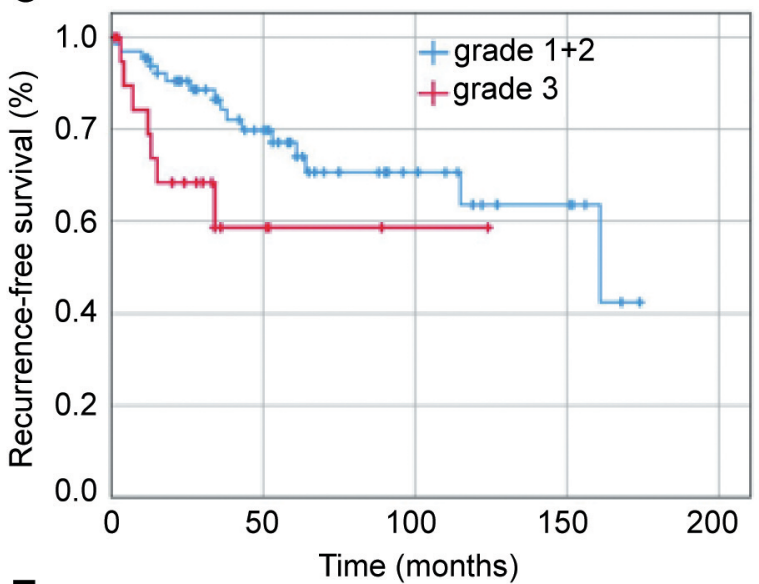

E

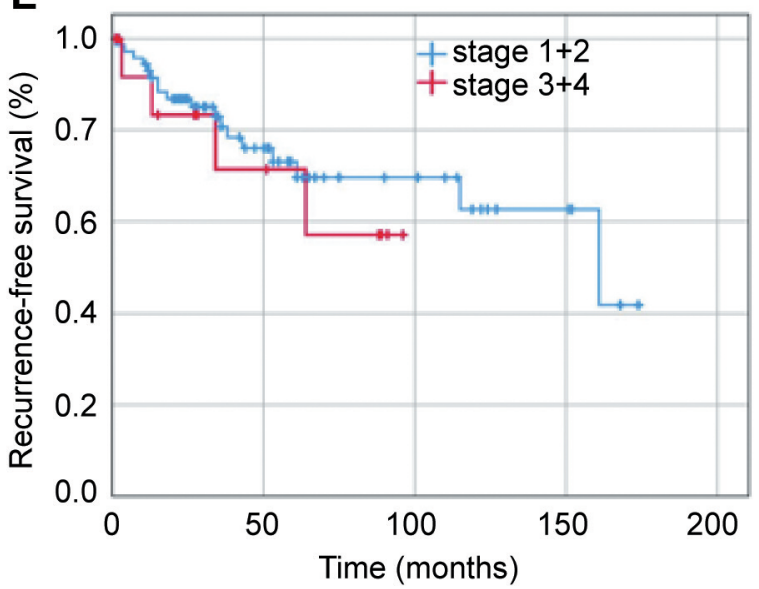

B

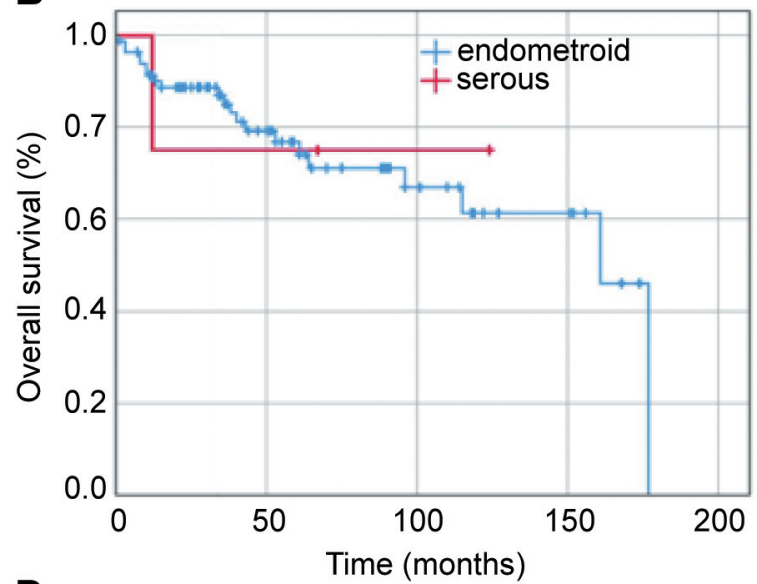

D

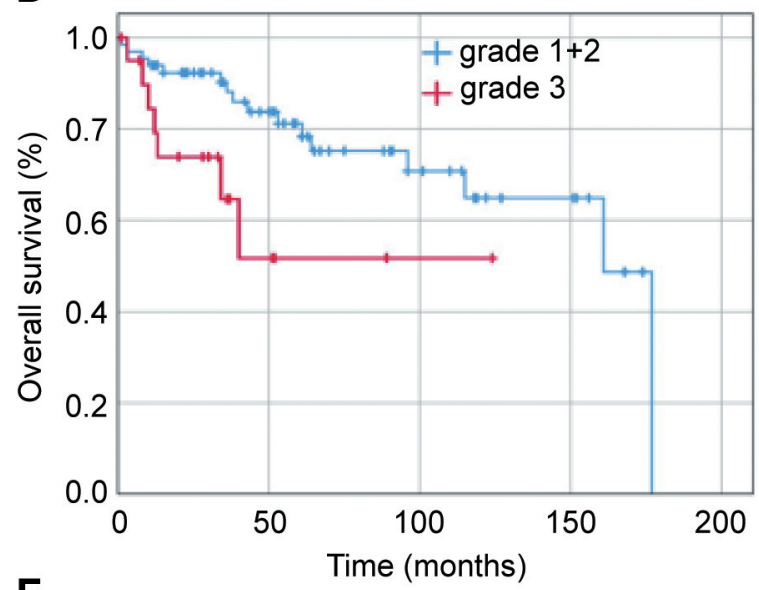

$\mathbf{F}$

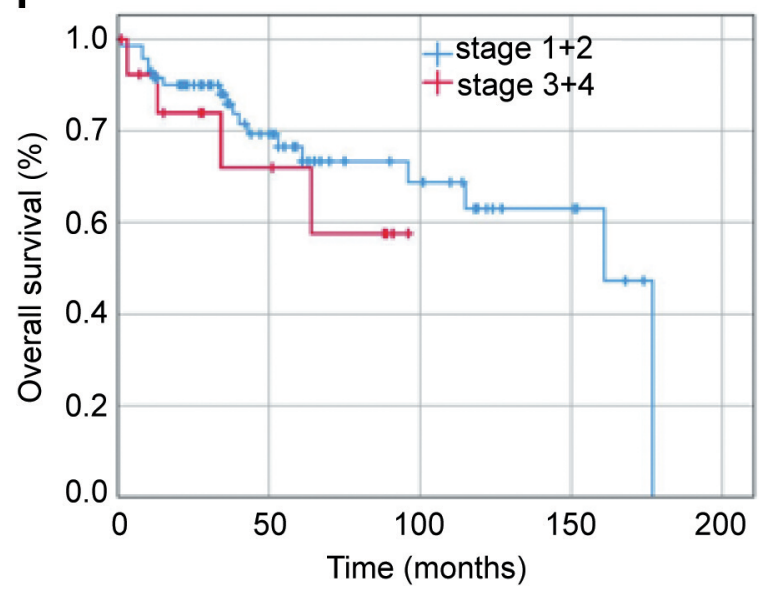

Figure 2. Kaplan-Meier survival analysis depending on the prognostic factors histological subtype (A and B), grading $(C$ and D), and tumor size $(E$ and $F)$. Recurrence-free survival $(A, C, E)$ and overall survival $(B, D, F)$ were evaluated.

areas, the relative B lymphocyte cell numbers in PD-L1 positive tumor areas are significantly higher than those of CD3 positive $\mathrm{T}$ lymphocytes (intratumoral: 19.0-fold; peritumoral: 7.6-fold).
These pronounced differences could not be detected for the CD68-positive cell population of monocytes and macrophages (Table VI). Examination of all 87 patients in the cohort demonstrated an equal number of CD68 positive 
Table III. Correlation of PD-L1 expression with tumor factors T3 + T4 stage tumors, lymph node status, p16, estrogen receptor, progesterone receptor, HER2/neu, and Ki-67.

\begin{tabular}{lcc}
\hline PD-L1 status & Negative (\%) & Positive (\%) \\
\hline & $72(82.8)$ & Correlated with PD-L1 (Chi-square test) \\
\hline & $\%$ of patients & 0.010 \\
T3+T4 stage tumors & 43.0 & 0.008 \\
Lymph node status positive & 86.0 & 0.001 \\
p16 status positive & 11.5 & 0.027 \\
Estrogen receptor negative & 9.2 & 0.002 \\
Progesterone receptor negative & 9.2 & 0.417 \\
HER2/neu positive & $\%$ of positive cells & Correlated with PD-L1 (t-Test) \\
\hline PD-L1 correlated with... & $0.09-79.5$ & 0.738 \\
\hline Ki-67 positive cells per preparation &
\end{tabular}

Table IV. Correlation of CD3-positive cells with PD-L1 positive and negative tumor tissue areas of intratumoral and peritumoral sections of EC samples.

\begin{tabular}{|c|c|c|c|c|}
\hline T Lymphocytes & \multicolumn{2}{|c|}{ Intratumoral } & \multicolumn{2}{|c|}{ Peritumoral } \\
\hline No. of evaluable cases & \multicolumn{2}{|c|}{86} & \multicolumn{2}{|c|}{84} \\
\hline Range & \multicolumn{2}{|c|}{$1-591$} & \multicolumn{2}{|c|}{$4-1,026$} \\
\hline PD-L1 status & Positive & Negative & Positive & Negative \\
\hline No. $(\%)$ & $14(16.3)$ & $72(83.7)$ & $13(15.5)$ & $71(84.5)$ \\
\hline $\mathrm{CD} 3$ positive cells (per $0.785 \mathrm{~mm}^{2}$ ) & 122 & 69 & 348 & 194 \\
\hline
\end{tabular}

Table V. Correlation of CD20-positive cells with PD-L1 positive and negative tumor tissue areas of intratumoral and peritumoral sections of EC samples.

\begin{tabular}{|c|c|c|c|c|}
\hline B Lymphocytes & \multicolumn{2}{|c|}{ Intratumoral } & \multicolumn{2}{|c|}{ Peritumoral } \\
\hline No. of evaluable cases & \multicolumn{2}{|c|}{86} & \multicolumn{2}{|c|}{86} \\
\hline Range & \multicolumn{2}{|c|}{$0-177$} & \multicolumn{2}{|c|}{$0-2,651$} \\
\hline PD-L1 status & Positive & Negative & Positive & Negative \\
\hline No. $(\%)$ & $14(16.3)$ & $72(83.7)$ & $15(17.4)$ & $71(84.5)$ \\
\hline CD20 positive cells (per $0.785 \mathrm{~mm}^{2}$ ) & 19 & 1 & 256 & 33 \\
\hline
\end{tabular}

No.: Number.

cells in PD-L1 positive and negative areas of intratumoral sections. In the peritumoral sections, 1.8-fold more CD68 positive cells were present in PD-L1 positive areas than in PD-L1 negative areas. According to Mann-Whitney $U$ analysis, there was only statistical significance in the CD68 positive signals of the peritumoral $(p=0.003)$, but not after analysis of the intratumoral sections $(p=0.353)$.

\section{Discussion}

$\mathrm{EC}$ is one of the most common gynaecological malignancies worldwide. With an annual incidence rate of 142,000 new cases, EC is the seventh most common malignant disease in women (2). Although some risk factors for EC initiation have already been identified, there is no effective screening for 
Table VI. Correlation of CD68-positive cells with PD-L1 positive and negative tumor tissue areas of intratumoral and peritumoral sections of EC samples.

\begin{tabular}{|c|c|c|c|c|}
\hline Monocytes/macrophages & \multicolumn{2}{|c|}{ Intratumoral } & \multicolumn{2}{|c|}{ Peritumoral } \\
\hline No. of evaluable cases & \multicolumn{2}{|c|}{87} & \multicolumn{2}{|c|}{87} \\
\hline Range & \multicolumn{2}{|c|}{$0-31$} & \multicolumn{2}{|c|}{$5-477$} \\
\hline PD-L1 status & Positive & Negative & Positive & Negative \\
\hline No. $(\%)$ & $15(17.2)$ & $72(82.8)$ & $15(17.2)$ & $72(82.8)$ \\
\hline CD68 positive cells (per $0.785 \mathrm{~mm}^{2}$ ) & 3 & 3 & 134 & 74 \\
\hline
\end{tabular}

No.: Number.

asymptomatic women in terms of early detection (14). Therefore, the therapy algorithm pays special attention to prognostic factors of EC. These factors can be used not only to predict the patient's prognosis but also to select the appropriate therapeutic option, if such factors do not even represent a new therapeutic target. EC-associated prognostic factors consist of long-established factors including histological subtype, grading, TNM and UICC classification, metastasis status, and lymph node involvement (15). Analysis of the present data set demonstrated that these established factors are also predictive for the EC cohort that was used. Survival analyses confirmed a significantly longer recurrence-free and overall survival for the low-aggressive tumor stages with endometroid histology and a lower grade and stage $(16,17)$.

A potential candidate marker for prognosis in EC is PD-L1. The immune-inhibitory factor has already been described as a predictive biomarker in several malignancies including lung, gastric, breast and renal cancer $(18,19)$. In EC tissue, PD-L1 expression is slightly increased compared to non-malignant endometrial tissue, but the prognostic power currently appears to be not definitively clarified (20-22). Acquisition of the PDL1 status in the present study showed $17.3 \%$ PD-L1 positive EC patients. Intratumoral PD-L1 expression correlated significantly with poorly differentiated tumors with stage T3 and T4 and positive lymph node status. Furthermore, the presence of PD-L1 also correlated with the expression of the oncogenic factor p16 and with the absence of the growth receptors estrogen receptor and progesterone receptor. However, assessment of the prognostic potential of PD-L1 by Cox regression suggested that PD-L1 represents a poor prognostic indicator compared with established markers. This observation is confirmed by a recent study of 53 EC cases (21).

EC cells can modulate the immune response of the tumor environment by up-regulating PD-1 activity and increasing expression of PD-L1 and PD-L2. Subsequently, both ligands bind to CD4 and CD8 positive tumor-infiltrating T cells and inhibits their antitumor activity by reducing proliferation, cytokine secretion, and cytotoxic ability $(23,24)$. However, unexpectedly, PD-L1 can also function as a tumor suppressor in aggressive EC cells. Up-regulated by a long noncoding RNA, overexpression of PD-L1 in aggressive EC cells causes a significant inhibition of cell invasiveness and motility (25).

Little is known about the molecular mechanisms of PD-L1 in EC cells. The factor interacts with the protein $\beta$-catenin which is responsible for cell motility and malignant signal transduction (26). Furthermore, bioinformatic analyses demonstrated that PD1/PD-L1 signaling pathways crucially control chemokines and signaling and effector proteins of immune cells (27). According to the widely accepted molecular EC subtyping by The Cancer Genome Atlas (TCGA) group, four distinct molecular EC subtypes can be defined, implying different prognoses for patients (5). Mutated polymerase $\varepsilon$ (POLE) subtype: A rare subtype characterised by a high number of mutations and with excellent prognosis across all disease stages. Micro-satellite instability (MSI) subtype: This subtype is characterised by mismatch repair deficiency, high mutation rates, and moderate prognosis. Copy number $(\mathrm{CN})$ low subtype: This endometrioid subtype shows intermediate good prognosis and includes all remaining tumors that do not meet the criteria of the other EC subgroups. CN high subtype: This subtype includes all serous EC cases and is accompanied by high levels of somatic copy number alterations and a poor prognosis. However, current studies do not yet allow clear conclusions on the extent to which these subtypes correlate with PD-L1 expression and may be particularly susceptible to therapeutic PD-L1 inhibition (28-31).

Another and at least as important aspect of tumorassociated PD-L1 expression is its potential therapeutic benefit. After binding to its receptor PD-1, PD-L1 suppresses the activation of immune cells, leading to local evasion from the immune system. Studies have shown that tumor zones with high PD-L1 expression rates also have a high lymphocyte density, however, that these lymphocytes are mostly inactive (32-34). By blocking this immune checkpoint with neutralizing antibodies against PD-1 or PD$\mathrm{L} 1$, the antitumoral immune response can be reactivated. Currently, this promising therapy option is being tested in a variety of malignancies and has already been approved for some cancer types (35). 
The major effect of immune checkpoint blockade by inhibition of the PD-1/PD-L1 axis is the reactivation of inactivated immune cells. Therefore, both the expression of PD-L1 in tumor cells as well as the infiltration of the tumor by immune cells are significant for this antitumor approach. The present study indicated that T lymphocytes, B lymphocytes, and monocytes/macrophages increased infiltration into PD-L1positive sections of both the tumor and its microenvironment. With the exception of the monocyte/macrophage evaluation of the positive intratumoral preparations, in which only very few CD68 positive cells could be detected in any case, significantly more immune cells were found in all PD-L1 positive intratumoral and peritumoral tumor sections than in the PD-L1 negative sections. However, the correlation of PD-L1 and immune cell infiltration was found to be statistically significant in only two cases (intratumoral CD20 positive cells, peritumoral CD68 positive cells). With respect to a potential application of PD-1/PD-L1 inhibitors for EC therapy, it can be stated on the basis of the data that in PD-L1 positive patients a significantly increased infiltration of the tumor tissue and especially of the tumor microenvironment with immune cells has occurred. The presence of lymphocytes, monocytes and macrophages is an important prerequisite for the antitumor efficacy of immune checkpoint blockade (36). Nevertheless, it is necessary to emphasize other relevant immune cell populations, e.g., FOXP3 positive regulatory T cells (37), which were not considered in the present analysis.

The fact that in a cohort of 87 EC patients only 15 patients $(17.3 \%)$ were PD-L1 positive may imply that only a minority of EC patients would benefit from immune checkpoint blockade directed against PD-1/PD-L1. Furthermore, this finding is consistent with the study by Gulec et al. who detected a percentage of $15.1 \%$ PD-L1 positive patients in 53 EC patients (21). In fact, however, it is far too early to make a conclusive statement of the overall efficacy of immune checkpoint blockade in EC. The main limitation of the present study is the retrospective monocentric study design with a relatively small number of patients. Therefore, significantly larger studies should be performed to evaluate the principle applicability of PD-1/PDL1 inhibitors in EC therapy. Furthermore, there is a clear evidence that inhibition of PD-1 can also exhibit anticancer effects in the absence of PD-L1 (11), although the alternative mechanisms of action are still largely unclear. Finally, PD-L1 functionality is not exclusively controlled by its expression level, but can also be controlled at the level of molecular regulation, for example by glycosylation of the protein (38).

\section{Conclusion}

In summary, the present study confirmed that PD-L1 expression was associated with the EC specific markers T3 + T4 stage, lymph node status, p16 expression, and the absence of estrogen and progesterone receptor. Moreover, the study demonstrated that although the immunosuppressive factor PD-L1 alone has no prognostic significance, it is certainly co-regulated with other oncogenic factors such as p16 and proliferative receptors. Expression of PD-L1 further indicates increased infiltration of tumor tissue and the tumor environment with immune cells. With regard to future immune checkpoint blockade EC therapies, PD-L1 status can be used to identify patients who respond to $\mathrm{PD}-1 / \mathrm{PD}-\mathrm{L} 1$ based therapy.

\section{Conflicts of Interest}

The Authors declare that they have no competing interests.

\section{Authors' Contributions}

Conceptualization, T.H., G.K., A.M.; methodology, T.H., T.T., J.H., L.O.; formal analysis, T.H., T.T., J.H., R.F., M.B.S.; investigation, T.H., T.T., J.H., F.R., H.G., T.M., C.S., E.K.E.; writing - original draft preparation, T.H., F.R., E.K.E., M.B.S.; writing - review and editing, G.K., M.B.S., A.M.; visualization, J.H., L.O., M.B.S.; supervision G.K., A.M.

\section{References}

1 Siegel RL, Miller KD and Jemal A: Cancer statistics, 2016. CA Cancer J Clin 66(1): 7-30, 2016. PMID: 26742998. DOI: 10.3322/caac. 21332

2 Battista MJ, Schmidt M, Eichbaum M, Almstedt K, Heimes AS, Mallmann P, Hoffmann G and Steiner E: Management of recurrent or metastatic endometrial cancer in Germany: results of the nationwide AGO pattern of care studies from the years 2013, 2009 and 2006. Arch Gynecol Obstet 292(6): 1355-1360, 2015. PMID: 26099624. DOI: 10.1007/s00404-015-3786-y

3 Suri V and Arora A: Management of endometrial cancer: a review. Rev Recent Clin Trials 10(4): 309-316, 2015. PMID: 26411949. DOI: $10.2174 / 1574887110666150923115228$

4 Bell DW and Ellenson LH: Molecular genetics of endometrial carcinoma. Annu Rev Pathol 14: 339-367, 2019. PMID: 30332563. DOI: 10.1146/annurev-pathol-020117-043609

5 Cancer Genome Atlas Research Network, Kandoth C, Schultz N, Cherniack AD, Akbani R, Liu Y, Shen H, Robertson AG, Pashtan I, Shen R, Benz CC, Yau C, Laird PW, Ding L, Zhang W, Mills GB, Kucherlapati R, Mardis ER and Levine DA: Integrated genomic characterization of endometrial carcinoma. Nature 497(7447): 67-73, 2013. PMID: 23636398. DOI: 10.1038/nature12113

6 Parra-Herran C, Lerner-Ellis J, Xu B, Khalouei S, Bassiouny D, Cesari M, Ismiil N and Nofech-Mozes S: Molecular-based classification algorithm for endometrial carcinoma categorizes ovarian endometrioid carcinoma into prognostically significant groups. Mod Pathol 30(12): 1748-1759, 2017. PMID: 28776572. DOI: $10.1038 /$ modpathol.2017.81

7 Keir ME, Butte MJ, Freeman GJ and Sharpe AH: PD-1 and its ligands in tolerance and immunity. Annu Rev Immunol 26: 677704, 2008. PMID: 18173375. DOI: 10.1146/annurev.immunol. 26.021607.090331

8 Thompson RH, Kuntz SM, Leibovich BC, Dong H, Lohse CM, Webster WS, Sengupta S, Frank I, Parker AS, Zincke H, Blute ML, Sebo TJ, Cheville JC and Kwon ED: Tumor B7-H1 is 
associated with poor prognosis in renal cell carcinoma patients with long-term follow-up. Cancer Res 66(7): 3381-3385, 2006. PMID: 16585157. DOI: 10.1158/0008-5472.CAN-05-4303

9 Hino R, Kabashima K, Kato Y, Yagi H, Nakamura M, Honjo T, Okazaki T and Tokura Y: Tumor cell expression of programmed cell death-1 ligand 1 is a prognostic factor for malignant melanoma. Cancer 116(7): 1757-1766, 2010. PMID: 20143437. DOI: $10.1002 /$ encr.24899

10 Nduom EK, Wei J, Yaghi NK, Huang N, Kong LY, Gabrusiewicz K, Ling X, Zhou S, Ivan C, Chen JQ, Burks JK, Fuller GN, Calin GA, Conrad CA, Creasy C, Ritthipichai K, Radvanyi L and Heimberger AB: PD-L1 expression and prognostic impact in glioblastoma. Neuro Oncol 18(2): 195-205, 2016. PMID: 26323609. DOI: $10.1093 /$ neuonc/nov 172

11 Sunshine J and Taube JM: PD-1/PD-L1 inhibitors. Curr Opin Pharmacol 23: 32-38, 2015. PMID: 26047524. DOI: 10.1016/ j.coph.2015.05.011

12 Horn LC, Schierle K, Schmidt D, Ulrich U, Liebmann A and Wittekind C: [Current TNM/FIGO classification for cervical and endometrial cancer as well as malignant mixed müllerian tumors. Facts and background]. Pathologe 32(3): 239-243, 2011. PMID: 20084383. DOI: 10.1007/s00292-010-1273-6

13 Moch H, Kononen T, Kallioniemi OP and Sauter G: Tissue microarrays: what will they bring to molecular and anatomic pathology? Adv Anat Pathol 8(1): 14-20, 2001. PMID: 11152090. DOI: 10.1097/00125480-200101000-00002

14 Raglan O, Kalliala I, Markozannes G, Cividini S, Gunter MJ, Nautiyal J, Gabra H, Paraskevaidis E, Martin-Hirsch P, Tsilidis KK and Kyrgiou M: Risk factors for endometrial cancer: An umbrella review of the literature. Int J Cancer 145(7): 17191730, 2019. PMID: 30387875. DOI: 10.1002/ijc.31961

$15 \mathrm{Lu} \mathrm{KH}$ and Broaddus RR: Endometrial cancer. N Engl J Med 383(21): 2053-2064, 2020. PMID: 33207095. DOI: 10.1056/ NEJMra1514010

16 Tejerizo-García A, Jiménez-López JS, Muñoz-González JL, Bartolomé-Sotillos S, Marqueta-Marqués L, López-González G and Gómez JF: Overall survival and disease-free survival in endometrial cancer: prognostic factors in 276 patients. Onco Targets Ther 9: 1305-1313, 2013. PMID: 24092993. DOI: 10.2147/OTT.S51532

17 Morice P, Leary A, Creutzberg C, Abu-Rustum N and Darai E: Endometrial cancer. Lancet 387(10023): 1094-1108, 2016. PMID: 26354523. DOI: 10.1016/S0140-6736(15)00130-0

18 Zhu X and Lang J: Soluble PD-1 and PD-L1: predictive and prognostic significance in cancer. Oncotarget 8(57): 97671-97682, 2017. PMID: 29228642. DOI: 10.18632/oncotarget.18311

19 Uhercik M, Sanders AJ, Owen S, Davies EL, Sharma AK, Jiang WG and Mokbel K: Clinical significance of PD1 and PDL1 in human breast cancer. Anticancer Res 37(8): 4249-4254, 2017. PMID: 28739716. DOI: 10.21873/anticanres.11817

20 Sungu N, Yildirim M, Desdicioglu R, Başaran Aydoğdu Ö, Kiliçarslan A, Tatli Doğan H, Kiliç Yazgan A, Akyol M and Erdoğan F: Expression of immunomodulatory molecules PD-1, PD-L1, and PD-L2, and their relationship with clinicopathologic characteristics in endometrial cancer. Int J Gynecol Pathol 38(5): 404-413, 2019. PMID: 30134343. DOI: 10.1097/PGP.0000000000000543

21 Kucukgoz Gulec U, Kilic Bagir E, Paydas S, Guzel AB, Gumurdulu D and Vardar MA: Programmed death-1 (PD-1) and programmed death-ligand 1 (PD-L1) expressions in type 2 endometrial cancer. Arch Gynecol Obstet 300(2): 377-382, 2019. PMID: 31076855. DOI: 10.1007/s00404-019-05180-2
22 Mo Z, Liu J, Zhang Q, Chen Z, Mei J, Liu L, Yang S, Li H, Zhou L and You Z: Expression of PD-1, PD-L1 and PD-L2 is associated with differentiation status and histological type of endometrial cancer. Oncol Lett 12(2): 944-950, 2016. PMID: 27446374. DOI: $10.3892 / 01.2016 .4744$

23 Vanderstraeten A, Tuyaerts S and Amant F: The immune system in the normal endometrium and implications for endometrial cancer development. J Reprod Immunol 109: 7-16, 2015. PMID: 25613542. DOI: 10.1016/j.jri.2014.12.006

24 Okazaki T and Honjo T: PD-1 and PD-1 ligands: from discovery to clinical application. Int Immunol 19(7): 813-824, 2007. PMID: 17606980. DOI: 10.1093/intimm/dxm057

$25 \mathrm{Xu}$ D, Dong P, Xiong Y, Chen R, Konno Y, Ihira K, Yue J and Watari H: PD-L1 is a tumor suppressor in aggressive endometrial cancer cells and its expression is regulated by miR216a and lncRNA MEG3. Front Cell Dev Biol 8: 598205, 2020. PMID: 33363153. DOI: 10.3389/fcell.2020.598205

26 Rowe M, Krishnan R, Mills A and Ring K: $\beta$-catenin and PDL1 expression in mismatch repair deficient endometrial carcinomas. Int J Gynecol Cancer 30(7): 993-999, 2020. PMID: 32376735. DOI: 10.1136/ijgc-2020-001239

27 Wang L, Liu Z, Zhang W, Zhang A and Qu P: PD-1 coexpression gene analysis and the regulatory network in endometrial cancer based on bioinformatics analysis. Biomed Res Int 2021: 9923434 , 2021. PMID: 34124265. DOI: 10.1155/2021/9923434

28 Le DT, Uram JN, Wang H, Bartlett BR, Kemberling H, Eyring AD, Skora AD, Luber BS, Azad NS, Laheru D, Biedrzycki B, Donehower RC, Zaheer A, Fisher GA, Crocenzi TS, Lee JJ, Duffy SM, Goldberg RM, de la Chapelle A, Koshiji M, Bhaijee F, Huebner T, Hruban RH, Wood LD, Cuka N, Pardoll DM, Papadopoulos N, Kinzler KW, Zhou S, Cornish TC, Taube JM, Anders RA, Eshleman JR, Vogelstein B and Diaz LA Jr: PD-1 blockade in tumors with mismatch-repair deficiency. N Engl J Med 372(26): 2509-2520, 2015. PMID: 26028255. DOI: 10.1056/NEJMoa1500596

29 Ott PA, Bang YJ, Berton-Rigaud D, Elez E, Pishvaian MJ, Rugo HS, Puzanov I, Mehnert JM, Aung KL, Lopez J, Carrigan M, Saraf S, Chen M and Soria JC: Safety and antitumor activity of pembrolizumab in advanced programmed death ligand 1-positive endometrial cancer: results from the KEYNOTE-028 study. J Clin Oncol 35(22): 2535-2541, 2017. PMID: 28489510. DOI: 10.1200/JCO.2017.72.5952

30 Mehnert JM, Panda A, Zhong H, Hirshfield K, Damare S, Lane K, Sokol L, Stein MN, Rodriguez-Rodriquez L, Kaufman HL, Ali S, Ross JS, Pavlick DC, Bhanot G, White EP, DiPaola RS, Lovell A, Cheng J and Ganesan S: Immune activation and response to pembrolizumab in POLE-mutant endometrial cancer. J Clin Invest 126(6): 2334-2340, 2016. PMID: 27159395. DOI: 10.1172/JCI84940

31 Santin AD, Bellone S, Buza N, Choi J, Schwartz PE, Schlessinger $\mathrm{J}$ and Lifton RP: Regression of chemotherapy-resistant polymerase $\varepsilon$ (POLE) ultra-mutated and MSH6 hyper-mutated endometrial tumors with nivolumab. Clin Cancer Res 22(23): 5682-5687, 2016. PMID: 27486176. DOI: 10.1158/1078-0432.CCR-16-1031

32 Li Z, Lai Y, Sun L, Zhang X, Liu R, Feng G, Zhou L, Jia L, Huang X, Kang Q, Lin D, Gao J and Shen L: PD-L1 expression is associated with massive lymphocyte infiltration and histology in gastric cancer. Hum Pathol 55: 182-189, 2016. PMID: 27260946. DOI: 10.1016/j.humpath.2016.05.012

33 Buisseret L, Garaud S, de Wind A, Van den Eynden G, Boisson A, Solinas C, Gu-Trantien C, Naveaux C, Lodewyckx JN, Duvillier 
H, Craciun L, Veys I, Larsimont D, Piccart-Gebhart M, Stagg J, Sotiriou C and Willard-Gallo K: Tumor-infiltrating lymphocyte composition, organization and PD-1/ PD-L1 expression are linked in breast cancer. Oncoimmunology 6(1): e1257452, 2016. PMID: 28197375. DOI: 10.1080/2162402X.2016.1257452

34 Abiko K, Matsumura N, Hamanishi J, Horikawa N, Murakami R, Yamaguchi K, Yoshioka Y, Baba T, Konishi I and Mandai M: IFN- $\gamma$ from lymphocytes induces PD-L1 expression and promotes progression of ovarian cancer. Br J Cancer 112(9): 1501-1509, 2015. PMID: 25867264. DOI: 10.1038/bjc.2015.101

35 Pardoll DM: The blockade of immune checkpoints in cancer immunotherapy. Nat Rev Cancer 12(4): 252-264, 2012. PMID: 22437870. DOI: $10.1038 / \mathrm{nrc} 3239$

36 Zhang L, Conejo-Garcia JR, Katsaros D, Gimotty PA, Massobrio M, Regnani G, Makrigiannakis A, Gray H, Schlienger K, Liebman MN, Rubin SC and Coukos G: Intratumoral T cells, recurrence, and survival in epithelial ovarian cancer. N Engl J Med 348(3): 203-213, 2003. PMID: 12529460. DOI: 10.1056/NEJMoa020177
37 Ghebeh H, Barhoush E, Tulbah A, Elkum N, Al-Tweigeri T and Dermime S: FOXP3+ Tregs and B7-H1+/PD-1+ T lymphocytes co-infiltrate the tumor tissues of high-risk breast cancer patients: Implication for immunotherapy. BMC Cancer 8: 57, 2008. PMID: 18294387. DOI: 10.1186/1471-2407-8-57

38 Wang YN, Lee HH, Hsu JL, Yu D and Hung MC: The impact of PD-L1 N-linked glycosylation on cancer therapy and clinical diagnosis. J Biomed Sci 27(1): 77, 2020. PMID: 32620165. DOI: $10.1186 / \mathrm{s} 12929-020-00670-\mathrm{x}$
Received October 29, 2021

Revised January 20, 2022

Accepted January 26, 2022 